\title{
"Twenty years of evidence-based coaching and onward into the future": Reflections on a conference
}

\author{
Sean O'Connor \\ Coaching Psychology Unit \\ School of Psychology \\ University of Sydney \\ Sydney, Australia
}

In February 2020, the University of Sydney Coaching Psychology Unit (CPU) held the $5^{\text {th }}$ Australian Evidence-Based Coaching Conference. The broad theme for the conference was "Twenty Years of Evidence-Based Coaching and Onward into the Future". The conference had two aims. The first was to celebrate 20 years of the CPU's contribution to coaching research and coach training. The second was to provide an opportunity to create connections, build relationships, and fuel thinking to propel evidence-based coaching into the future. This special issue of Philosophy of Coaching will hopefully act as a catalyst for making the second aim a reality.

The Evidence-Based Coaching Conference was held over 2 days, with over 70 speakers presenting to 400 delegates, across more than 30 sessions. Themed sessions included evidence-based approaches to practice, student and academic research reports, symposiums on the future of coaching, coaching education, coaching supervision, along with perspectives and thought leadership on coaching approaches. As a result, conference presenters tackled a wide variety of topics and a number of common themes emerged that I believe will establish the conference as a tipping point towards a productive, positive future for evidence-based coaching. Before I identify these themes, I think it is important that we reflect on the context within which the conference occurred, and within which these first set of outcomes and proceedings now finds itself.

In the lead up to the conference, the mood in the coaching community (particularly in Sydney) was one of excited anticipation. We (the CPU) were celebrating the $20^{\text {th }}$ anniversary of our Masters in Coaching Psychology program and many past and present students where very much looking forward to the event as a way of connecting with old (and new) colleagues and friends, based on a shared valuing of an evidence-based approach to coaching practice.

This is an Open Access article distributed under the terms of the Creative Commons Attribution (CC BY) License which permits use, distribution and reproduction in any medium, provided the original work is properly cited. 
It is this approach that established the CPU as the world's first dedicated tertiary-level coach training and research unit.

\section{A Time of Trial}

At the time, much of Australia had experienced the very visceral and devastating effects of climate change and was beginning to emerge from several months of bushfires that had ravaged much of the nation. Given this, the organising committee was wrestling with the question of how we would be best to recognise the tension and continued unrelenting stress experienced by so many over the proceeding months. Unbeknownst to many, the Director of the CPU - Emeritus Professor Anthony Grant - had been battling cancer for some time and become seriously ill after Christmas 2019.

Tragically, Tony passed away on the $3^{\text {rd }}$ of February 2020, a mere two weeks before the conference. A conference that he not only played a major part in organizing, but was very much looking forward to attending.

From a personal perspective, Tony was a dear friend, colleague and mentor. Academically, his work has been hugely influential in the creation of a thriving global evidence-based coaching industry. He provided a stream of important and significant contributions to psychological science and has helped raise the academic and scientific standing of coaching across the globe. His work will continue to positively influence the field for many, many years to come. While Tony's academic impact can to some extent be measured, it is not possible to gauge the positive impact he has had on the lives of individuals, groups, families and organisations. His intelligence, his compassion and his BIG personality created (in my mind) a contagious effect on others, the extent of which can never be known, but will surely live on in the hearts and minds of those he came into contact with.

The loss of Tony rippled through the coaching community, a community that was preparing to reconnect around shared values, passion and experience. A community that was looking to learn and grow. A community looking towards the future and hoping to take the next steps together in creating a number of important pathways for the future of evidence-based coaching. For many, this conference may have marked a beginning for that journey. A community that would now come together in the midst of grief and loss, but also seek to build a sense of hope (as Tony would have wanted).

And come together they did. 
The conference was astonishing on many levels. To my mind this had little to do with anything special we did as an organising committee, but much more to do with how the community came together. Hearts were opened, brains were switched on and whilst there was a palpable sense of shared loss, an atmosphere of celebration did prevail; a celebration of Tony's remarkable life and the CPU's many accomplishments, Indeed, in his final days, Tony made a specific request for the conference to be a celebration, and his wish was granted by a dedicated band of volunteers, who worked hard to create just that. The overwhelming feedback I have received was that it was a wonderfully rewarding experience with many challenging conversations, sparked through the conference, continuing to this day.

\section{The Conference}

I am pleased to say that there were many fabulous presentations delivered at the conference, a selection of which are showcased in this special issue. After reviewing the comments and feedback from delegates, and reflecting on my own experience, I feel a number of clear themes emerged. The first was a very strong call to action for the coaching community. A question of responsibility to those we coach, the organisations we coach within, and the broader communities and societies we exist within. Second, questions of purpose arose regarding the potential impact of evidence-based coaching. A sense that it was time for an examination of our own philosophies and practices, which might enable us as a community to provide so much more. To impact positively and with purpose. To push between the tension in ways that permit creativity, and possibility to emerge more productively. As one participant put it, "a developmental shift of the coaching profession seemed to be taking place".

The conference was infused with a warm sense of community and connectedness, along with a willingness to challenge our thinking in the service of collective growth. I believe the challenging circumstances surrounding the conference contributed to the needs supportive atmosphere, which is of course an ideal climate for growth.

Perhaps more than any conference I have been to, this one ended with a feeling of possibility and potential. Many new connections had been formed, both between people and within minds. People were excited about what could come next. Little did we know the COVID-19 pandemic was soon to be upon us, skewing the plans of many, shifting our thinking and slowing momentum as people pivoted towards matters of personal safety and survival. But now, as the world slowly recovers and we seek to reconnect, I would like to put out another 
call to action. For those of you who were at the conference, or who are reading this special issue, what will you choose to do with your learning?

It is time for a developmental shift in the coaching landscape, one that will require hard work and focus. Indeed, we will need to redouble our efforts if we are to reignite the excitement and possibility cultivated at the conference, which is something I hope readers can glimpse from what is presented here.

\section{A Note of Thanks}

I would like to take this opportunity to thank all those involved in organising and running the conference, most especially the dedicated volunteers who worked so hard and gave so much of their time. Whilst there are far too many to name individually, a few deserve a special mention. This includes the wonderful Ingrid Studholme, along with Susan Theo Stewart, Aimee Wells and Lucas Finch. Their tireless coordination and support brought the conference into existence. Thank you also to the University of Sydney Coaching and Mentoring Alumni president, Jo Topler, for her efforts organising additional social events and volunteer groups. Thank you to the academic committee, especially Dr Michael Cavanagh and Dr Gordon Spence, who began the journey with us and followed it through many twists and turns. Special thanks also go to the presenters and contributors (many who travelled great distance) who provided challenging, inspiring content and helped to scaffold thinking. Finally, to the participants. Many thanks for creating a climate of shared challenge and support. Your willingness to engage, contribute and come together was a shining example of how wonderful the coaching community can be and a reminder of how lucky we are to work in this way with so many.

In many ways I saw this conference as something of an end point. A celebration of all that had been done. For many of the reasons mentioned here it became much more than that. A node in time that both reflected on the past, challenged our current state and hinted at possible future pathways. The challenge now, as always, is about the path we chose to take next.

Finally, I would like to thank Dr Gordon Spence and Dr Paul Lawrence for putting this special issue together through such trying times. Hopefully this ripple from the conference will build into a wave that will benefit the coaching community for many years to come. 